\title{
Evaluating changes in student health, wellbeing and social circumstances before and during COVID-19 pandemic restrictions in Australia
}

\author{
Dannielle Post ${ }^{1}$, Agnes Vitry $^{2}$, Katherine Baldock ${ }^{\text {Corresp. } 3}$ \\ ${ }^{1}$ Allied Health and Human Performance, Alliance for Research in Exercise, Nutrition and Activity (ARENA), University of South Australia, Adelaide, South \\ Australia, Australia \\ ${ }^{2}$ Clinical and Health Sciences, Australian Centre for Precision Health (ACPreH), University of South Australia, Adelaide, South Australia, Australia \\ ${ }^{3}$ Allied Health and Human Performance, Australian Centre for Precision Health (ACPreH), University of South Australia, Adelaide, South Australia, Australia \\ Corresponding Author: Katherine Baldock \\ Email address: katherine.baldock@unisa.edu.au
}

The impacts of COVID-19 have been felt on a global scale, with associated physical distancing restrictions and economic downturn having flow-on effects for mental health and wellbeing across the community, and for university students in particular. First-year pharmaceutical and medical science students completing a common introductory population health course at an Australian university are routinely surveyed at the beginning of the semester as part of the course. Survey data inform teaching approaches based on understanding the 'real life' commitments and health profiles of students, and deidentified data form part of the teaching material. The 2020 student cohort was invited to complete a second follow-up survey during COVID-19 physical distancing restrictions. A total of $n=126$ students completed both the initial and follow-up surveys ( $50.6 \%$ response rate), and $n=99$ (39.8\% of the total cohort) consented for their data to be included in research. There was a non-significant decrease in student employment; however, $22 \%$ of all students reported loss of work due to COVID-19. There was a statistically significant decrease in the proportion of students undertaking sufficient levels of physical activity, and a statistically significant increase in reported family stressors associated with loss of employment or an inability to gain employment between March and May 2020. Two-thirds of respondents reported increased stress as an impact of the transition to online learning. Implementation of holistic strategies, incorporating attention to additional factors influencing students' capacity to engage in study, and which may have long-term impacts across the life of the degree program, should be considered. 
1 Evaluating changes in student health, wellbeing and social circumstances before and

2 during COVID-19 pandemic restrictions in Australia

3

4 Dannielle Post ${ }^{1}$, Agnes Vitry ${ }^{2}$, Katherine L. Baldock ${ }^{3}$

$6 \quad{ }^{1}$ UniSA: Allied Health and Human Performance, Alliance for Research in Exercise, Nutrition

7 and Activity (ARENA), University of South Australia, Adelaide, South Australia, Australia

$8{ }^{2}$ UniSA: Clinical and Health Sciences, Australian Centre for Precision Health (ACPreH),

9 University of South Australia, Adelaide, South Australia, Australia

$10{ }^{3}$ UniSA: Allied Health and Human Performance, Australian Centre for Precision Health

11 (ACPreH), University of South Australia, Adelaide, South Australia, Australia

14 Corresponding author:

15 Katherine Baldock ${ }^{3}$

16 City East Campus, University of South Australia, Adelaide SA 5001

17 Email: $\underline{\text { Katherine.Baldock@unisa.edu.au }}$

19 Total word count: 3568 words (including tables and reference list) 


\section{Abstract}

21 The impacts of COVID-19 have been felt on a global scale, with associated physical distancing

22 restrictions and economic downturn having flow-on effects for mental health and wellbeing

23 across the community, and for university students in particular. First-year pharmaceutical and

24 medical science students completing a common introductory population health course at an

25 Australian university are routinely surveyed at the beginning of the semester as part of the

26 course. Survey data inform teaching approaches based on understanding the 'real life'

27 commitments and health profiles of students, and deidentified data form part of the teaching

28 material. The 2020 student cohort was invited to complete a second follow-up survey during

29 COVID-19 physical distancing restrictions. A total of $n=126$ students completed both the initial

30 and follow-up surveys (50.6\% response rate), and $n=99(39.8 \%$ of the total cohort) consented for

31 their data to be included in research. There was a non-significant decrease in student

32 employment; however, $22 \%$ of all students reported loss of work due to COVID-19. There was a

33 statistically significant decrease in the proportion of students undertaking sufficient levels of

34 physical activity, and a statistically significant increase in reported family stressors associated

35 with loss of employment or an inability to gain employment between March and May 2020.

36 Two-thirds of respondents reported increased stress as an impact of the transition to online

37 learning. Implementation of holistic strategies, incorporating attention to additional factors

38 influencing students' capacity to engage in study, and which may have long-term impacts across

39 the life of the degree program, should be considered.

41 Keywords: university student wellbeing, mental health, social circumstances/determinants,

42 COVID-19, pharmaceutical and medical science students 


\section{Introduction}

44 The impacts of COVID-19 have been felt on a global scale, with the associated social distancing

45 restrictions and economic downturn having a flow-on effect on mental health and wellbeing

46 across all levels of the community. While some positives have been reported anecdotally as a

47 result of social distancing measures, such as the flexibility of working from home, being able to

48 spend more time with household family members, and reduced stress as a result of not having to

49 attend or ferry children to extracurricular activities, there is growing evidence for increases in

50 psychological issues such as anxiety and depression (Fisher et al., 2020).

51 The negative impact of COVID-19 has been felt in the university sector and for university

52 students in particular (Dodd et al., 2021). This has manifested in many ways, from international

53 students being unable to travel to other countries to attend university, students concerned about

54 graduating on time, first year students adjusting to life at university, and for many students in

55 general, transitioning from on campus, face-to-face modes of delivery to the online learning

56 environment. A study of 1,000 Greek university students identified increased anxiety,

57 depression, and suicidal thoughts associated with the impact of COVID-19 (Kaparounaki et al.,

58 2020). Similar psychological findings were reported in a study of 2,530 Spanish university staff

59 and students, with greater impact for students compared to staff (Odriozola-González et al.,

60 2020). Evidence for psychological distress and an acute stress response was also demonstrated in

61 a study of 1,442 Chinese health students (Li et al., 2020), and a cross-sectional analysis of 787

62 Australian university students demonstrated low wellbeing and negative experiences related to

63 online learning (Dodd et al., 2021).

64 It is anticipated that other factors, such as the loss of casual income due to the associated

65 economic downturn, housing concerns, food insecurity, the need for social distancing and its link 
66 to social isolation, and the competing demands of family responsibilities, further exacerbate the

67 capacity of domestic and international students to thrive at university (Defeyter et al., 2020;

68 Morris et al., 2020). Additionally, while the shift to online learning may suit some students, it

69 brings with it concerns around equity for students who may not have access to stable internet

70 connections or suitable places to study (Dodd et al., 2021; Hammond et al., 2020).

71 Since 2015, first year pharmaceutical and medical science students completing a common, on-

72 campus introductory population health course at an Australian university, have been routinely

73 surveyed at the beginning of the semester as part of their enrolment in the course. The survey,

74 largely modelled on national population-based surveys in Australia such as the National Health

75 Survey, collects data about the students' sociodemographic background, their lifestyle and health

76 behaviours, and chronic disease status. These data are intended to inform teaching approaches

77 that are based on understanding the 'real life' commitments and health profiles of students, to

78 better provide teaching environments that enhance students' learning experience and capacity to

79 learn. Additionally, deidentified data forms part of the teaching content for the course, enabling

80 teaching about concepts such as the social determinants of health and practical skills in working

81 with data. In late March 2020, the university ceased face-to-face education, in line with public

82 health recommendations. As a means of understanding the impact of COVID-19 on students'

83 capacity to engage with university studies during the pandemic, the 2020 student cohort was

84 invited to complete a follow-up survey in the midst of COVID-19 pandemic physical distancing

85 restrictions. This paper describes the outcomes of that survey. 


\section{Materials and Methods}

89 Students enrolled in a first-year introductory population health course across the pharmacy and

90 medical science degrees for the first semester of $2020(n=249)$, were invited by email, in the first

91 week of teaching at the start of the course (March 2020), to complete the survey routinely

92 administered at the start of this course each year. Students were subsequently invited by email in

93 May 2020 to complete a second online follow-up survey. The emails included information about

94 the specific purpose of each survey and the voluntary nature of survey completion was explained

95 to the students. Consent for both surveys was implied by the completion and submission of the

96 survey by the student. Students were asked to complete the survey within three weeks, with a

97 reminder email sent after 7-10 days. Students indicated their consent for their data to be used for

98 research purposes via a single question in each survey. Approval for this study was provided by

99 the University of South Australia's Human Research Ethics Committee (protocol number:

$100 \quad 0000034112)$.

\section{Survey characteristics}

102 Students completed two online surveys, the second being slightly adapted from the original

103 yearly-completed survey, to capture the impact of COVID-19 on lifestyle and health behaviours,

104 employment status, and capacity to undertake study. The surveys elicited general

105 sociodemographic information (e.g., age, gender identify, postcode of residence, height and

106 weight), self-rated health, physical activity behaviour (based on the IPAQ (SF) (Craig et al.,

107 2003)), smoking status, fruit and vegetable intake, health service and medication use, mental

108 health diagnoses, family stressors, and income and expenses. Questions in the follow-up survey

109 focused on impacts of COVID-19 such as employment, asking students if their employment

110 status had been impacted by COVID-19, and if so, how they were managing the loss of income; 
111 and housing, regarding whether their living arrangements had been impacted. Students were

112 asked to identify the specific factors that had impacted their learning experience during COVID-

11319 restrictions, and to provide information about the effect of the transition from face-to-face to

114 online learning on their studies. An open-ended question asked students to provide information

115 about the positive and negative impacts of COVID-19 on their lifestyle. The remaining questions

116 required students to provide either a yes/no answer (e.g., Do you currently smoke?), a specific

117 numerical value (e.g., How many times did you do moderate physical activity in the last week?),

118 or to select from a series of answers (e.g., Are you currently in any form of paid employment? 1.

119 No, 2. Yes: Full time, 3. Yes: Part time, 4. Yes: Casual). Surveys were piloted with staff and then

120 students prior to administration. The survey is provided as a supplementary file.

121 Data analysis

122 Quantitative data were described using median and interquartile range (IQR) for continuous data

123 that were not normally distributed, and proportions for categorical data. Differences in

124 sociodemographic and health-related factors between March and May 2020 were examined for

125 paired data using Wilcoxon Signed Rank Test for continuous data and the McNemar test for

126 categorical data. All analyses were performed using IBM SPSS Statistics, version 25. Statistical

127 significance was set at $\alpha=0.05$.

\section{Results}

129 A total of $n=126$ enrolled students completed both the March and the May 2020 online surveys,

130 representing a $50.6 \%$ response rate, and $\mathrm{n}=99(39.8 \%$ of the total cohort $)$ provided consent for

131 their data to be used for research purposes. Respondents had a median age of 18 years 
132 (interquartile range $(\mathrm{IQR})=2$ ), and $70.3 \%$ were female. Sociodemographic characteristics are

133 reported in Table 1.

134 Almost half (46.5\%) of the student cohort were in some form of paid employment at the

135 commencement of semester; however, $22.2 \%$ of all respondents reported experiencing loss of

136 employment due to the COVID19 pandemic. It is possible that some students, in contrast,

137 gained employment between the start of semester and May 2020, since there was no statistically

138 significant difference in the proportion of students reporting to be employed between March

139 (46.5\%) and May (39.4\%) 2020 amongst student respondents.

140 There was a non-significant decrease in the proportion of students reporting having a regular

141 source of income, and a non-significant increase in the proportion of students receiving money or

142 income from other sources, such as an allowance from parents. A total of $9 \%$ of the respondents

143 reported having changed accommodation due to the COVID-19 pandemic, however there was no

144 significant change in the reported expenditure on housing costs. Respondents reported a

145 statistically significant $25 \%$ decrease in the amount they spent in total each week on housing,

146 transport, food, entertainment and mobile phone bills ( $\mathrm{p}=0.002)$.

147 There was a significant decrease $(\mathrm{p}=0.004)$ in the percentage of students being sufficiently

148 physically active and the percentage of students visiting the dentist $(\mathrm{p}=0.010)$, and significant

149 increases for family stressors related to 'not able to get a job' $(\mathrm{p}=0.004)$ and 'involuntary job

150 loss' $(\mathrm{p}<0.001)$. There was no significant change in psychological factors, nor were there

151 significant changes for other health-related characteristics, health service use, or family stressors

152 (Tables 2 and 3). 
153 The most commonly reported COVID-specific factors related to studying in the online

154 environment were decreased motivation (88.89\%), feeling isolated from peers $(82.83 \%)$,

155 increased difficulties in understanding course content (72.73\%), and increased stress (66.67\%).

156 The most commonly reported impacts of social distancing measures were lack of interaction with

157 peers $(85.86 \%)$, deferment of practical classes $(65.66 \%)$, and lack of communication with

158 teaching staff (57.58\%) (Table 4).

159 The open-ended question was completed by nine students (10\%). Perceived positive aspects of

160 COVID-19 included being able to spend more time in the fresh air; more time for exercise;

161 preferences for more courses to be available online; having extra time to study due to reduced

162 travel time; and establishing a routine and becoming used to studying at home, albeit

163 accompanied by anxiousness about returning to on-campus learning. Negative perceptions of the

164 impact of COVID-19 related to issues with access to online teaching technologies, that resulted

165 in the student having to withdraw from courses; the home environment not being conducive to

166 study; not being able to maintain an exercise routine due to limited resources; decreased working

167 hours and loss of income; feelings of isolation from fellow students; and juggling parenting 168 responsibilities with study and work responsibilities.

\section{Discussion}

170 The purpose of this study was to understand the impact of the COVID-19 pandemic and

171 associated factors on the capacity of first year university students to engage with university

172 studies. We believe that this may be one of only a few studies that compares data collected pre-

173 and-mid pandemic in the same cohort of students, and the only one in Australia, where lockdown

174 duration has not been as prolonged as that in the northern hemisphere. The findings would

175 suggest that while there was a non-significant trend for changes in employment and housing 
176 arrangements for the students themselves, family stressors associated with loss of employment or

177 an inability to gain employment were significant. The change in these factors in the two-months

178 between completion of each survey likely reflects the impact of COVID-19 on employment

179 circumstances at the global level.

180 Physical activity, in the form of students meeting physical activity guidelines of 150 minutes of

181 moderate-to-vigorous physical activity per week (UK CMO Guidelines Writing Group, 2019),

182 was significantly reduced in this cohort. This may be due in part to the onset of cooler weather at

183 the time of the pandemic; however, the closure of gymnasiums as well as changes in active

184 transport are also likely to be contributing factors. These findings are similar to those of a UK

185 study, that demonstrated reduced physical activity and increased sedentary time for students,

186 across a nine-month period (Savage et al., 2021). Another study of university students reported a

$18730 \%$ decrease in physical activity compared to students in previous cohorts (Gallo et al., 2020).

188 The significant change in students consulting the dentist may be due to the six-to-twelve monthly

189 cycle of such visits; however, it is likely that this was due to restrictions outlined by the

190 Australian Government, including deferment of all routine dental examinations and treatment

191 (Australian Health Protection Principal Committee, 2020).

192 There was no evidence of change in dietary behaviour nor was there identification of food

193 insecurity in this cohort; however, almost 70\% of respondents live with their parents which may

194 be a protective factor. Other research suggests that students living independently are more likely

195 to have low levels of food security (Defeyter et al., 2020), and a Canadian study has provided

196 evidence that university students not living with their parents had poorer diets during COVID

197 (Bertrand et al., 2021). These findings also differ from those of Gallo et al. (2020) who found 
198 female university students had a higher energy intake than female comparators in the previous

199 year's cohort and in comparison to their male counterparts in the same cohort.

200 While there were some positives associated with the pandemic, factors such as decreased

201 motivation, feelings of isolation from peers, and increased difficulties in understanding course

202 content, as well as technological issues, and home environments that are not conducive to study

203 may impact the ability of students to successfully undertake university studies. These factors

204 reflect factors raised in recent studies (Dodd et al., 2021; Hammond et al., 2020). Further, while

205 there were no significant changes in psychological factors in the current study, students did

206 report increased stress. Similar findings demonstrating perceptions of increased stress have been

207 reported in a UK study, although in contrast to our findings, this study also showed significant

208 decreases in mental wellbeing (Savage et al., 2021). This may reflect the ongoing lockdown

209 requirements experienced in the UK, compared to Australia, or may relate to the longer duration

210 between pre-and-post measures in the UK study. Many universities have taken steps to support

211 the study needs of students during COVID-19; however, the implementation of strategies that

212 provide a holistic approach, incorporating the additional factors influencing students' capacity to

213 engage in study, which may have long-term impacts across the life of the degree program, should

214 be considered.

\section{Limitations}

216 One limitation of this study is that students were asked to self-report a previous diagnosis of

217 mental illness. Instead, application of a validated tool such as the Kessler-10 (Kessler \&

218 Mroczek, 1992) may have provided a more accurate impact of COVID-19 on students'

219 psychological wellbeing. The small number of students who responded to the open-ended

220 question means that perceptions of the broader negative and positive impacts of COVID-19 are 
221 not generalisable to the student population. Further, this study did not distinguish between

222 domestic and international students, which may have impacted the findings. Beyond this, the

223 small sample size predisposes the study to type II error.

\section{Conclusion}

225 This study has described the impact of transition to the online learning environment, and social

226 distancing measures, as a result of the COVID-19 pandemic. A number of factors have been

227 identified that likely impact the capacity of students to successfully undertake university studies

228 during pandemic-like circumstances. Longitudinal studies should be undertaken to investigate

229 the impact of such factors on the short and longer-term retention of students and students'

230 achievement at university. 
231 Table 1. Sociodemographic characteristics $(n=99)$

\begin{tabular}{|c|c|c|c|}
\hline & $\begin{array}{l}\text { Survey } 1 \text { (Mar } \\
\text { 2020) }\end{array}$ & $\begin{array}{l}\text { Survey } 2 \text { (May } \\
\text { 2020) }\end{array}$ & \\
\hline Sociodemographic factor & $\begin{array}{l}\text { \% or median } \\
\text { (IQR) }\end{array}$ & $\begin{array}{l}\text { \% or median } \\
\text { (IQR) }\end{array}$ & p-value ${ }^{1}$ \\
\hline Currently in paid employment: Yes & $46.5 \%$ & $39.4 \%$ & 0.14 \\
\hline Employment loss due to COVID19: Yes & - & $22.2 \%$ & \\
\hline \multicolumn{4}{|l|}{ Housing situation } \\
\hline Live with parents/guardians & $68.7 \%$ & $69.7 \%$ & 1.00 \\
\hline Live independently (alone or with others) & $31.3 \%$ & $30.3 \%$ & \\
\hline Changed accommodation due to COVID19: Yes & - & $9.1 \%$ & \\
\hline Have a regular source of income: Yes & $49.5 \%$ & $43.4 \%$ & 0.29 \\
\hline $\begin{array}{l}\text { Receive money or income from other sources (e.g., allowance from parents): } \\
\text { Yes }\end{array}$ & $39.4 \%$ & $47.5 \%$ & 0.15 \\
\hline Responsible for paying mobile phone account: Yes & $51.5 \%$ & $55.6 \%$ & 0.23 \\
\hline Average weekly expenditure: transport ${ }^{2}$ & $\$ 45(40)$ & $\$ 5(40)$ & $<0.001$ \\
\hline
\end{tabular}




\begin{tabular}{|c|c|c|c|}
\hline Average weekly expenditure: food $^{2}$ & $\$ 50(72)$ & $\$ 50(90)$ & 0.16 \\
\hline Average weekly expenditure: housing ${ }^{2}$ & $\$ 0(164)$ & $\$ 0(162)$ & 0.25 \\
\hline Average weekly expenditure: entertainment ${ }^{2}$ & $\$ 20(60)$ & $\$ 0(50)$ & 0.08 \\
\hline Average weekly expenditure: mobile phone ${ }^{2}$ & $\$ 5(8)$ & $\$ 5(12)$ & 0.20 \\
\hline Total average weekly expenditure ${ }^{2}$ & $\$ 200(271)$ & $\$ 150(304)$ & 0.002 \\
\hline Total weekly income ${ }^{2}$ & $\$ 231(329)$ & $\$ 231(326)$ & 0.41 \\
\hline
\end{tabular}

$233{ }^{1}$ p-value based on related-samples Wilcoxon Signed Rank Test or McNemar's test.

$234{ }^{2}$ A total of $\mathrm{n}=53$ students provided complete data on income and expenditure.

Table 2. Health-related characteristics $(n=99)$

\begin{tabular}{|l|c|c|}
\hline & Survey 1 (Mar & Survey 2 (May \\
\hline Health-related factors & 2020) & 2020) \\
\hline Physical activity & \% or median & or median \\
(IQR) & p-value \\
\hline
\end{tabular}




\begin{tabular}{|c|c|c|c|}
\hline Sufficiently active & $44.4 \%$ & $30.3 \%$ & 0.004 \\
\hline Insufficiently active / Sedentary & $50.5 \%$ & $63.6 \%$ & \\
\hline Not stated $^{1}$ & $5.1 \%$ & $6.1 \%$ & \\
\hline Vegetables (usual serves per day) & $2(1)$ & $3(2)$ & 0.35 \\
\hline Fruit (usual serves per day) & $2(1)$ & $2(1)$ & 0.76 \\
\hline \multicolumn{4}{|l|}{ Self-rated health } \\
\hline Fair or Poor & $12.1 \%$ & $11.1 \%$ & 0.74 \\
\hline Good, Very Good or Excellent & $87.9 \%$ & $88.9 \%$ & \\
\hline BMI & $22.0(5.1)$ & $21.7(5.1)$ & 0.54 \\
\hline \multicolumn{4}{|c|}{$\begin{array}{l}\text { Family stressors: Have any of these been a problem for you or anyone close to } \\
\text { you, during the last } 12 \text { months? }\end{array}$} \\
\hline Serious illness & 19.2 & 20.2 & 1.00 \\
\hline Serious accident & 5.1 & 5.1 & 1.00 \\
\hline Death of family member or close friend & 23.2 & 25.3 & 0.79 \\
\hline Mental illness & 21. & 28.3 & 0.23 \\
\hline Serious disability & 2.0 & 1.0 & 1.00 \\
\hline
\end{tabular}




\begin{tabular}{|c|c|c|c|}
\hline Divorce or separation & 11.1 & 12.1 & 1.00 \\
\hline Not able to get a job & 13.1 & 27.3 & 0.004 \\
\hline Involuntary loss of job & 4.0 & 27.3 & $<0.001$ \\
\hline Alcohol or drug-related problem & 10.1 & 8.1 & 0.75 \\
\hline Witness to violence & 5.1 & 4.0 & 1.00 \\
\hline Abuse or violent crime & 4.0 & 3.0 & 1.00 \\
\hline Trouble with the police & 2.0 & 3.0 & 1.00 \\
\hline Gambling problem & 0.0 & 0.0 & NA \\
\hline \multicolumn{4}{|l|}{ Diagnosed mental health conditions } \\
\hline Stress & $12.1 \%$ & $12.1 \%$ & 1.00 \\
\hline Anxiety & $20.2 \%$ & $19.2 \%$ & 1.00 \\
\hline Depression & $14.1 \%$ & $11.1 \%$ & 0.51 \\
\hline Other mental health condition & $3.0 \%$ & $3.0 \%$ & 1.00 \\
\hline Currently experiencing diagnosed mental health condition: Yes & $20.7 \%$ & $22.7 \%$ & 0.75 \\
\hline
\end{tabular}

${ }^{1}$ Category 'Not stated' not included in testing differences in proportions between the March and May 2020 surveys.

Table 3. Health service use $(n=99)$ 


\begin{tabular}{|c|c|c|c|}
\hline & $\begin{array}{c}\text { Survey } 1 \text { (Mar } \\
\text { 2020) }\end{array}$ & $\begin{array}{c}\text { Survey } 2 \text { (May } \\
\text { 2020) }\end{array}$ & \\
\hline Health service use & $\%$ & $\%$ & p-value \\
\hline \multicolumn{4}{|l|}{ In the last 12 months: } \\
\hline Consulted GP & 70.7 & 67.7 & 0.51 \\
\hline Consulted specialist & 17.2 & 18.2 & 1.00 \\
\hline Consulted dentist & 56.6 & 42.4 & 0.01 \\
\hline Consulted other health professional & 22.2 & 17.2 & 0.30 \\
\hline Admitted to hospital as an inpatient & 5.1 & 3.0 & 0.69 \\
\hline Visited an outpatient clinic & 4.0 & 4.0 & 1.00 \\
\hline Visited emergency/casualty hospital department & 7.1 & 7.1 & 1.00 \\
\hline Visited day clinic & 15.2 & 12.1 & 0.58 \\
\hline
\end{tabular}


241 Table 4. Impact of COVID-specific factors: transitioning to the online learning environment and social distancing measures ( $\mathrm{n}=99)$

\begin{tabular}{|c|c|}
\hline Factor & $\%$ \\
\hline \multicolumn{2}{|l|}{ Impact of transition to online learning environment } \\
\hline Decreased motivation & 88.9 \\
\hline Increased motivation & 14.1 \\
\hline Increased stress & 66.7 \\
\hline Decreased stress & 21.2 \\
\hline Increased difficulties in understanding course content & 72.7 \\
\hline Decreased difficulties in understanding course content & 9.1 \\
\hline Feeling isolated from teaching staff & 61.6 \\
\hline Feeling isolated from peers & 82.8 \\
\hline \multicolumn{2}{|l|}{ Impact of social-distancing measures } \\
\hline Lack of adequate workspace at home & 38.4 \\
\hline Insufficient internet access & 25.3 \\
\hline Lack of access to on-campus services (e.g., library, computer pools) & 24.2 \\
\hline Lack of communication with teaching staff (e.g., lecturers / tutors) & 57.6 \\
\hline
\end{tabular}




\begin{tabular}{|l|c|}
\hline Lack of interaction with peers & 85.9 \\
\hline Deferment of classes (e.g., practicals) & 65.7 \\
\hline Changes to assessments & 49.5 \\
\hline Difficulty accessing necessary course material & 23.2 \\
\hline
\end{tabular}


244

245

246

247

248

249

250

251

252

253

254

255

256

257

258

259

260

261

262

263

264

265

266

267

268

269

270

271

272

273

274

275

276

277

278

279

280

281

282

283

284

\section{References}

Australian Health Protection Principal Committee. (2020). A statement from the Australian Health Protection Principal Committee about school immunisation programs and dental services. https://www.health.gov.au/news/australian-health-protection-principalcommittee-ahppc-advice-to-national-cabinet-on-25-march-2020

Bertrand, L., Shaw, K. A., Ko, J., Deprez, D., Chilibeck, P. D., \& Zello, G. A. (2021). The impact of the coronavirus disease 2019 (COVID-19) pandemic on university students' dietary intake, physical activity, and sedentary behaviour. Applied Physiology, Nutrition, and Metabolism, 46(3), 265-272. https://doi.org/10.1139/apnm-2020-0990 \%M 33449864

Craig, C., Marshall, A., Sjostrom, M., Bauman, A., Booth, M., Ainsworth, B., Pratt, M., Ekelund, U., Yngve, A., Sallis, J., \& Oja, P. (2003). International Physical Activity Questionnaire: 12-Country Reliability and Validity. Medicine \& Science in Sports \& Exercise, 35(8), 1381-1395. https://doi.org/10.1249/01.Mss.0000078924.61453.Fb

Defeyter, G., Stretesky, P., Long, M., Furey, S., Reynolds, C., Dodds, A., Porteous, D., Mann, E. J., Stretesky, C., Kemp, A., Fox, J., \& McAnallen, A. (2020). Food Insecurity and Lived Experience of Students (FILES). . https://openaccess.city.ac.uk/id/eprint/24283/

Dodd, R. H., Dadaczynski, K., Okan, O., McCaffery, K. J., \& Pickles, K. (2021). Psychological Wellbeing and Academic Experience of University Students in Australia during COVID19. International Journal of Environmental Research and Public Health, 18(3), 866. https://www.mdpi.com/1660-4601/18/3/866

Fisher, J. R., Tran, T. D., Hammarberg, K., Sastry, J., Nguyen, H., Rowe, H., Popplestone, S., Stocker, R., Stubber, C., \& Kirkman, M. (2020). Mental health of people in Australia in the first month of COVID-19 restrictions: a national survey. Medical Journal of Australia, 213(10), 458-464. https://doi.org/https://doi.org/10.5694/mja2.50831

Gallo, L. A., Gallo, T. F., Young, S. L., Moritz, K. M., \& Akison, L. K. (2020). The impact of isolation measures due to COVID-19 on energy intake and physical activity levels in Australian university students. medRxiv, 2020.2005.2010.20076414. https://doi.org/10.1101/2020.05.10.20076414

Hammond, T., Watson, K., Brumbelow, K., Fields, S., Shryock, K., Chamberland, J.-F., Barroso, L., de Miranda, M., Johnson, M., Alexander, G., Childs, M. D., Ray, S., White, L., Cherian, J., Dunn, A., \& Herbert, B. (2020). A Survey to Measure the Effects of Forced Transition to 100\% Online Learning on Community Sharing, Feelings of Social Isolation, Equity, Resilience, and Learning Content During the COVID-19 Pandemic. T. A. M. University. https://oaktrust.library.tamu.edu/handle/1969.1/187835

Kaparounaki, C. K., Patsali, M. E., Mousa, D.-P. V., Papadopoulou, E. V. K., Papadopoulou, K. K. K., \& Fountoulakis, K. N. (2020). University students' mental health amidst the COVID-19 quarantine in Greece. Psychiatry Research, 290, 113111. https://doi.org/https://doi.org/10.1016/j.psychres.2020.113111

Kessler, R. C., \& Mroczek, D. (1992). 'An Update of the Development of Mental Health Screening Scales for the US National Health Interview Study'. 
Li, Y., Wang, Y., Jiang, J., Valdimarsdóttir, U. A., Fall, K., Fang, F., Song, H., Lu, D., \& Zhang, W. (2020). Psychological distress among health professional students during the COVID19 outbreak. Psychol Med, 1-3. https://doi.org/10.1017/s0033291720001555

Morris, A., Mitchell, E., \& Ramia, G. (2020). Why coronavirus impacts are devastating for international students in private rental housing. . The Conversation. https://theconversation.com/why-coronavirus-impacts-are-devastating-for-internationalstudents-in-private-rental-housing-134792

Odriozola-González, P., Planchuelo-Gómez, Á., Irurtia, M. J., \& de Luis-García, R. (2020). Psychological effects of the COVID-19 outbreak and lockdown among students and workers of a Spanish university. Psychiatry Research, 290, 113108. https://doi.org/https://doi.org/10.1016/j.psychres.2020.113108

Savage, M. J., Hennis, P. J., Magistro, D., Donaldson, J., Healy, L. C., \& James, R. M. (2021). Nine Months into the COVID-19 Pandemic: A Longitudinal Study Showing Mental Health and Movement Behaviours Are Impaired in UK Students. International Journal of Environmental Research and Public Health, 18(6), 2930. https://www.mdpi.com/1660$\underline{4601 / 18 / 6 / 2930}$

UK CMO Guidelines Writing Group. (2019). UK Chief Medical Officers' Physical Activity Guidelines. London: Gov UK Retrieved from https://assets.publishing.service.gov.uk/government/uploads/system/uploads/attachment $\underline{\text { data/file/829841/uk-chief-medical-officers-physical-activity-guidelines.pdf }}$ 